\title{
Impact of Multiple Altimeter Data and Mean Dynamic Topography in a Global Analysis and Forecasting System
}

\author{
MATHIEU HAMON \\ Mercator Ocean, Ramonville-Saint-Agne, France \\ ERIC GREINER \\ CLS, Ramonville-Saint-Agne, France \\ PIERRE-YVES LE TRAON \\ Mercator Ocean, Ramonville-Saint-Agne, and IFREMER, Plouzané, France \\ ELISABETH REMY \\ Mercator Ocean, Ramonville-Saint-Agne, France
}

(Manuscript received 9 January 2019, in final form 17 April 2019)

\begin{abstract}
Satellite altimetry is one of the main sources of information used to constrain global ocean analysis and forecasting systems. In addition to in situ vertical temperature and salinity profiles and sea surface temperature (SST) data, sea level anomalies (SLA) from multiple altimeters are assimilated through the knowledge of a surface reference, the mean dynamic topography (MDT). The quality of analyses and forecasts mainly depends on the availability of SLA observations and on the accuracy of the MDT. A series of observing system evaluations (OSEs) were conducted to assess the relative importance of the number of assimilated altimeters and the accuracy of the MDT in a Mercator Ocean global $1 / 4^{\circ}$ ocean data assimilation system. Dedicated tools were used to quantify impacts on analyzed and forecast sea surface height and temperature/ salinity in deeper layers. The study shows that a constellation of four altimeters associated with a precise MDT is required to adequately describe and predict upper-ocean circulation in a global $1 / 4^{\circ}$ ocean data assimilation system. Compared to a one-altimeter configuration, a four-altimeter configuration reduces the mean forecast error by about $30 \%$, but the reduction can reach more than $80 \%$ in western boundary current (WBC) regions. The use of the most recent MDT updates improves the accuracy of analyses and forecasts to the same extent as assimilating a fourth altimeter.
\end{abstract}

\section{Introduction}

Altimetry data are considered to be the most important input for assimilation systems. After several geophysical corrections, an accurate estimation of alongtrack sea surface height ( $\mathrm{SSH}$ ) is derived from altimeter measurements. Anomalies of SSH with respect to a surface reference [sea level anomalies (SLAs)] are used to constrain 3D ocean forecasts by means of a data assimilation scheme. Over the past 20 years, several studies have pointed out that multiple altimeter missions

Corresponding author: Mathieu Hamon, mathieu.hamon@ mercator-ocean.fr are required to adequately represent ocean eddies and associated currents in models (Le Traon et al. 2017).

As early as 2001, Ducet and Le Traon (2001) showed that a combination of at least two altimeters is required to solve the main oceanic spatial and time characteristics. Pascual et al. $(2006,2007)$ used a varying combination of four altimeters (Jason-1, ERS-2, TOPEX/ Poseidon, and Geosat Follow-On) to produce objective analysis of the global ocean and the Mediterranean Sea, respectively. These studies show that at least three but preferably four altimeters are required to monitor mesoscale ocean circulation. In the Mediterranean basin, the addition of a second altimeter reduced the analyzed velocity errors by a factor of 2.2 , and by 1.5 with a 
third altimeter. More recently, Oke et al. (2015) compiled several studies that illustrated the impacts of multiple altimeters in two regional eddy-resolving analysis and forecasting systems. The assimilation of a third altimeter reduced the error in analyzed SSH by $3 \%$ in the Bluelink Reanalysis (BRAN; version 3) system (Oke et al. 2013) and the Mediterranean Forecasting System (MFS; Tonani et al. 2009; Oddo et al. 2009). The role of multiple altimeters has also been illustrated by Lea et al. (2014) in the global assimilating system Forecasting Ocean Assimilation Model (FOAM; Storkey et al. 2010). The authors showed that the removal of an altimeter from a three-altimeter constellation results in an overall $4 \%$ increase in the forecast SSH error. In addition to the impact on SSH, the study also pointed out that the removal of the third altimeter causes smallscale changes in temperature and salinity in the interior ocean. The importance of multiple altimeter missions in the Mercator Ocean system has also been illustrated by Verrier et al. (2017) using an observing system simulations experiment (OSSE) approach. A series of experiments with the Mercator Ocean $1 / 4^{\circ}$ system have been carried out using three altimeters simulated using a high-resolution model. Overall, the forecast error is reduced by $10 \%$ by adding a third simulated altimeter to this system. The results show that maximum improvements have occurred in areas with high dynamics such as western boundary currents.

One fundamental requirement for assimilating SLA in ocean models is accurate knowledge of the mean dynamic topography (MDT; Rio et al. 2005, 2011, 2014). Theoretically, MDT is the difference between the mean sea surface (MSS) and the Earth geoid. Thanks to more than 25 years of altimetry observations, the MSS is known with centimeter accuracy at spatial scales down to $10-20 \mathrm{~km}$. Although the Gravity Field and SteadyState Ocean Circulation Explorer (GOCE) satellite and the Gravity Recovery and Climate Experiment (GRACE) missions provide measurements of Earth's gravity field, the effective resolution of the geoid observations does not allow direct computation of the MDT. The increase in the number of in situ observations (expendable bathythermograph, Argo, and drifter velocities) have made it possible to estimate the reference height from observations alone (without using a dynamic model), as in Rio et al. $(2011,2014)$. Another method would be to use the time-average statistics from a dynamical model. In the early years of altimetry era, because of a lack of adequate observation, this technique was applied by Greiner and Périgaud (1994) to assimilate Geosat data. This average was not accurate, and it was optimized during assimilation. This principle of using analysis systems to estimate the reference height by assimilating altimeter anomalies and in situ observations has been adopted subsequently, for example, in Lea et al. (2008).

The purpose of this study is twofold. The first objective is to evaluate the impact of the number of altimeters in the global Mercator Ocean analysis and forecasting system, a complex system that jointly assimilates different types of data through a multivariate assimilation scheme. The second objective is to assess the impact of assimilating different MDT solutions and to intercompare all the results. This is achieved through an observing system evaluation (OSE) approach. We conducted a series of experiments in which only one parameter/ dataset was modified. Dedicated tools were then used to compare sea level, temperature, and salinity and to analyze forecast errors at different spatial scales. The general idea of the paper is to provide elements to guide future studies for a better use of altimetry data in assimilation systems.

The paper is organized as follows. Section 2 describes the ocean model, the data assimilation scheme, and the assimilated data. The experimental design and impact assessment tools are detailed in sections 3 and 4 . The impacts of the number of assimilated altimeters and the MDT are assessed in section 5. This section focuses particularly on sea level forecast errors, forecast skills, and ocean variability at different spatial scales. It also addresses impacts on temperature and salinity findings in the water column. All results are summarized and the main conclusions are presented in section 6 .

\section{Experimental setup}

\section{a. Model}

In this study, we use the ocean general circulation model (OGCM) NEMO (Madec et al. 2008) in a global $1 / 4^{\circ}$-resolution configuration. The OGCM configuration is identical to that used in Mercator Ocean's operational forecasting system. More details on the model configuration can be found in Lellouche et al. (2013).

The horizontal resolution corresponds to a varying gridcell size between $27 \mathrm{~km}$ at the equator and $6 \mathrm{~km}$ near the Weddell Sea. The water column is discretized using 50 unevenly spaced levels in a partial step parameterization. The resolution thereby decreases with depth, from $1 \mathrm{~m}$ at the surface to $450 \mathrm{~m}$ in deep layers until it adapts to the shape of the bottom depth. The model is forced by 3 -hourly, $1 / 2^{\circ}$-horizontal-resolution European Centre for Medium-Range Weather Forecasts (ECMWF) atmospheric fields from the Integrated Forecasting System (IFS) using the CORE bulk formulation (Large and Yeager 2009). The usual set of atmospheric variables is taken into account: surface air temperature, surface 
humidity, mean sea level pressure, and wind at $10 \mathrm{~m}$. Downward longwave and shortwave radiative fluxes and rainfall (solid plus liquid) fluxes are also used in the surface heat and freshwater budget. Last, the system does not include tides.

\section{b. Assimilation scheme}

The data assimilation system used in this study is an updated version of Système d'Assimilation Mercator, version 2 (SAM2), described by Lellouche et al. (2013) and Verrier et al. (2017), which is used operationally at Mercator Ocean. The SAM2 data assimilation method relies on a reduced-order Kalman filter based on the singular evolutive extended Kalman filter (SEEK) with a 7-day assimilation window (referred to as the assimilation cycle). For each assimilation cycle, SAM2 produces increments of $\mathrm{SSH}$, temperature, salinity, and velocity (zonal and meridional components) computed from the differences between the model forecast and the observations, weighted by the forecast error covariance and the observation error. In the operational system, the observation error is locally modulated by the Desroziers ratio (Desroziers et al. 2005) computed in the previous cycle. Increments are applied as a tendency term in the model prognostic equations using the incremental analysis update (IAU) method (Bloom et al. 1996; Benkiran and Greiner 2008).

In the updated version of SAM2 that was used here, the assimilation scheme was configured in $4 \mathrm{D}$ mode. Three increments are computed for days 2, 4, and 6 (only one in the operational configuration, positioned in the middle of the assimilation window). Unlike the operational version of SAM2, the forecast error covariance matrix is derived from the statistics of a set of 3D oceanstate anomalies (previously computed from the global $1 / 4^{\circ}$ free simulation) varying each day in the assimilation window. For each day, the assimilation system selects about 300 smoothed model anomaly fields.

In this study, observation errors were set at the beginning of the experiment and remained constant over time (no adaptive tuning of the observation error).

\section{c. Altimetry data and mean dynamic topography}

In addition to in situ and SST data, SLA along-track delayed-time data produced by the Copernicus-Marine Environment Monitoring Service (CMEMS) sea level Thematic Assembly Centre (TAC) are assimilated in the experiments. During the 1-yr period from mid-2014 to mid-2015, there were four nadir altimeters available: Jason-2 (J2), CryoSat-2 (C2), Haiyang-2A (Hy2) and Ka-band Altimeter (AltiKa)/Satellite with Argos and AltiKa [SARAL $(A l)]$. For all SLA datasets, dynamic atmospheric correction (DAC), oceanic tide correction, and long wavelength error (LWE) correction were applied. To reduce measurement noise, SLA data were filtered with a Lanczos low-pass filter (cutoff at $65 \mathrm{~km}$ ). For the needs of the assimilation, SLA data were also resampled every $14 \mathrm{~km}$ along the tracks. Because of the different characteristics of the instruments, altimeters have different levels of noise. As recommended by the data center supplier, the instrumental error of $J 2$ and $\mathrm{Al}$ were set at 2 and $4 \mathrm{~cm}$ for $C 2$ and $H y 2$.

Altimeter anomalies cannot be assimilated in a model without a reference level. The Mercator Ocean's method to estimate the MDT falls between the observation approach used by Rio et al. $(2011,2014)$ and the model approach used by Greiner and Périgaud (1994). System's outputs are used to iteratively correct the first guess of a MDT. To make this unique estimate, we use the system with the best observations. These are reanalysis, which are carried out in delayed time with reprocessed observations (altimetry and in situ). The model has the advantage of solving barotropic motions (which are not estimated by current in situ observations). The advantage is that we get an estimate at the equator, at high latitudes, very close to the coast, or even under the ice. Moreover, this estimate can be made at the model resolution, while the estimates from the GRACE + GOCE observations struggle to go below $100 \mathrm{~km}$.

The iterative process used at Mercator Ocean was started with the use of the observed MDT (RIO09). This MDT has been corrected with the reanalysis GLORYS2V1 (over the period 2004-11), using GRACE + GOCE data (2011). This MDT (MDTv2), which is at $1 / 12^{\circ}$ resolution, is the oldest tested in this article. This MDT was used in the GLORYS2V3 reanalysis. The period 200413 is used, with GRACE + GOCE (2014) data, the observed MDT CNES_CLS13, as well as World Ocean Atlas 2013 (WOA13) deep climatology data to form the MDTv3 estimate. The latter was used in the GLORYS12V1 reanalysis. The period 2004-16 is used, with GRACE + GOCE data (2017), as well as WOA13 deep climatology data to form the MDTv4 estimate. The upto-date MDTv4 and the difference when compared to the previous solutions of MDTv2 and MDTv3 are shown in Fig. 1. The a priori error on MDT is presented in Fig. 1b. In addition to the instrumental errors, it forms the $2 \mathrm{D}$ observation error on SLA data in the system.

The assimilation of SLA observations requires an observation operator, in order to be able to compare the model with the observations. In Mercator Ocean systems, these are mainly space-time filters (Lellouche et al. 2018b). The daily mean of the model's SSH is first calculated. High-frequency barotropic signals are then removed in the same way as for altimetry data processing (Carrère and Lyard 2003; Dibarboure et al. 2011). 


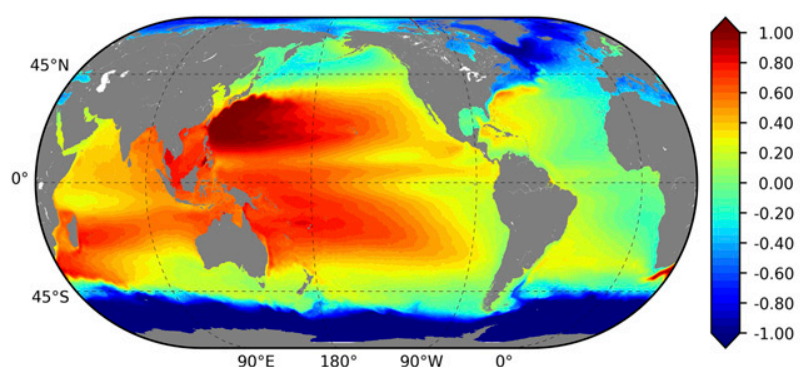

(a)

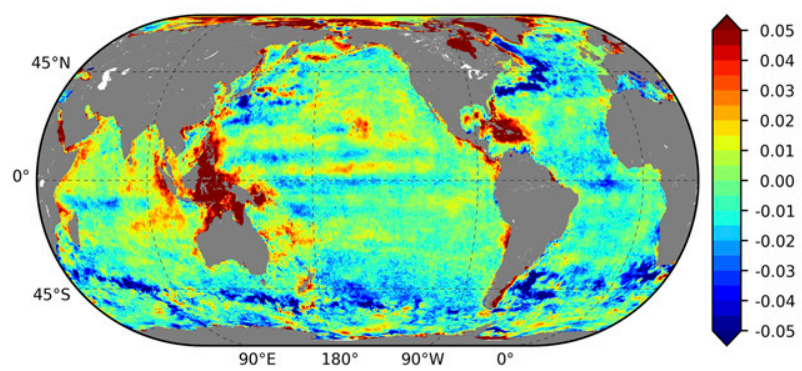

(c)

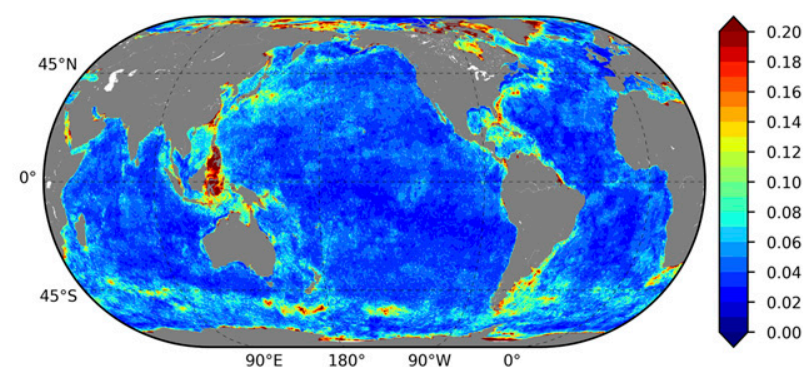

(b)

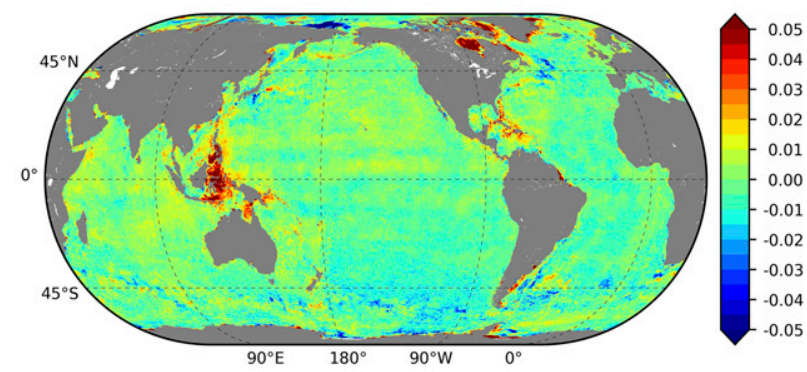

(d)

FIG. 1. (a) MDTv4, (b) its associated error, and differences (c) MDTv4 - MDTv2 and (d) MDTv4 - MDTv3 (m).

Finally, the MDT at the observation locations is removed to obtain the model SLA.

\section{Observing system experiments design}

Six 1-yr-long OSEs were produced for the period from 21 May 2014 to 20 May 2015. All the OSEs assimilate SST maps and in situ vertical temperature and salinity profiles. For each assimilation cycle, we assimilate on the third day, the SST map coming from the daily NOAA Reynolds $0.25^{\circ}$ product, computed from Advanced Very High Resolution Radiometer (AVHRR) observations (Reynolds et al. 2007). To avoid correlation issues between observations, only one point out of four is assimilated. SST maps are therefore decimated in a $1^{\circ} \times 1^{\circ}$ grid. The in situ temperature and salinity profiles are from the CORA4.1 (Cabanes et al. 2013) in situ database provided by the CMEMS in situ TAC. Since the in situ platform provides high-frequency observations, subsampling is applied: only one profile per day and within a $0.1^{\circ}$ distance is assimilated.

The only difference between OSEs is the number of assimilated altimeters and/or the MDT used as the surface reference (see Table 1). In the first four OSEs (OSE1v4-OSE4v4), SLA along-track data from $J 2, C 2$, $\mathrm{Hy} 2$, and $\mathrm{Al}$ are integrated successively into the assimilation system. In these experiments, the up-to-date MDTv4 was used. In OSE4v2 and OSE4v3, four altimeters were assimilated but MDTv2 and MDTv3, respectively, were used.
All OSEs start from the states of a 6-month spinup run where all available data and MDTv4 have been assimilated. The spinup experiment was initialized from the World Ocean Atlas 2013 (version 2) temperature (Locarnini et al. 2013) and salinity (Zweng et al. 2013) climatology fields.

\section{Diagnostic tools}

In this section, we present mathematical formulations of the diagnostic tools used to quantify the differences between the different OSEs. Impacts can first be quantified in terms of forecast errors (square of the innovation, observations minus forecasts). At the observation point, we assess the impact on forecasts between an OSE and a reference experiment by computing the difference of forecast errors (DFE):

$$
\begin{aligned}
\operatorname{DFE}_{k, l}(t, i, j) & =B\left\{\text { FCSTerror }_{k}-\text { FCSTerror }_{l}\right\} \\
& =B\left\{\left[H\left(X_{k}\right)-y\right]^{2}-\left[H\left(X_{l}\right)-y\right]^{2}\right\},
\end{aligned}
$$

TABLE 1. Computed simulations and assimilated dataset.

\begin{tabular}{cccccc}
\hline & Jason-2 & CryoSat-2 & Haiyang-2A & SARAL & MDT \\
\hline OSE1v4 & $\times$ & & & & MDTv4 \\
OSE2v4 & $\times$ & $\times$ & & & MDTv4 \\
OSE3v4 & $\times$ & $\times$ & $\times$ & & MDTv4 \\
OSE4v4 & $\times$ & $\times$ & $\times$ & $\times$ & MDTv4 \\
OSE4v2 & $\times$ & $\times$ & $\times$ & $\times$ & MDTv2 \\
OSE4v3 & $\times$ & $\times$ & $\times$ & $\times$ & MDTv3 \\
\hline
\end{tabular}


where $H$ represents the observation operator, $X$ the forecast field, and $y$ the observation. The box-averaging operator $B$ is used to spatially represent the DFE values. It averages the geolocated data in $2^{\circ} \times 2^{\circ}$ regular boxes of coordinates $(i, j)$. A positive DFE indicates that the forecast error in the OSE $k$ is higher than in the OSE $l$.

Since the variability of the ocean is not homogeneous, it may be interesting to compare spatially normalized quantities. We then propose to define the normalized difference of forecast errors (NDFE) as the ratio of the DFE to the local temporal variability of the ocean during the assimilation cycle. At each cycle, the ocean's variability, Ocean Var $(t, i, j)$, is estimated with the analyzed SSH fields from the four-altimeters experiment OSE4v4:

$$
\operatorname{NDFE}_{k, l}(t, i, j)=\frac{\operatorname{DFE}_{k, l}(t, i, j)}{\operatorname{OceanVar}(t, i, j)} .
$$

The use of the forecast skills metric also provides valuable information. Like the NDFE metric, it is also a normalized forecast error, but it allows for assessment of the model's ability to predict by comparing it to the persistence. This metric also has the advantage of being commonly used, especially in meteorology, and can easily be compared. The forecast skill is defined as

$$
\begin{aligned}
\text { FCSTskill(day) } & =1-\frac{\text { FCSTerror(day) }}{\operatorname{MSpersistence}(\text { day })} \\
& =1-\frac{\left[H\left(X_{\text {day }}\right)-y\right]^{2}}{\left[H\left(X_{\text {day }=0}\right)-y\right]^{2}}
\end{aligned}
$$

\section{Impacts}

This section presents the results obtained by comparing the different OSEs. In all experiments, the four altimeters were integrated into the system (but not necessarily assimilated) in order to have comparisons at exactly the same locations in each OSE. SSH diagnostics show the direct impact of altimetry data. In addition to the surface height assessment, statistics over the water column are computed comparing integrated temperature and salinity errors at the location of in situ data. These comparisons also allow us to check the consistency between the different datasets, as the different variables are linked through the model and the multivariate assimilation scheme. Finally, an energy spectrum analysis complements this analysis in order to assess the impacts of SSH assimilation at different spatial scales.

\section{a. Forecast errors}

In this section, we assess the impacts of changing a component (number of altimeters/MDT) of the

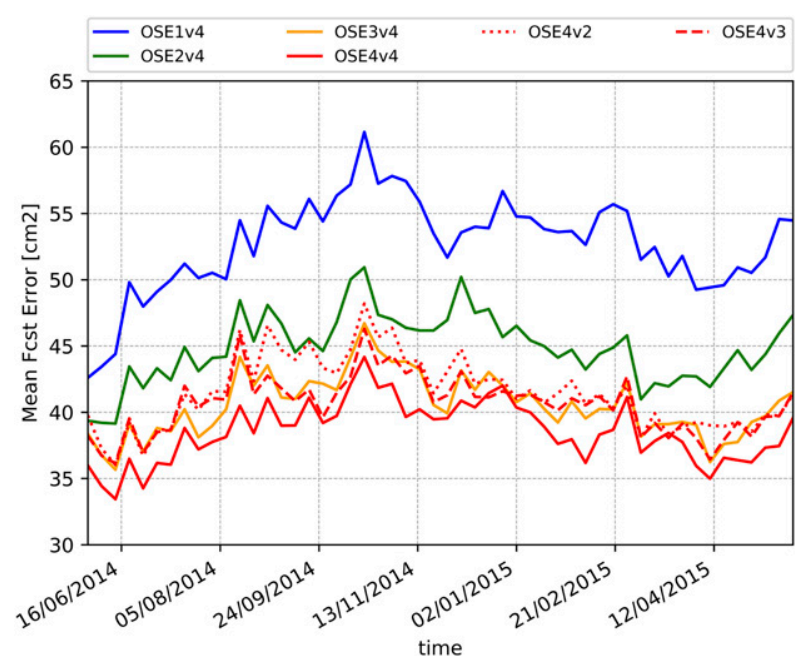

FIG. 2. Time series of globally averaged forecast errors from the different OSEs.

observation system by comparing forecast errors, DFEs [Eq. (1)] and NDFEs [Eq. (2)]. Figure 2 shows the time series of forecast errors for the different OSEs. First of all, if we consider only OSE1v4-OSE4v4 (full lines), the global average of forecast errors is significantly reduced by adding altimetry data. For example in October, when overall errors are highest, moving from one to four assimilated altimeters allows the forecast system to progressively reduce the errors from more than $60 \mathrm{~cm}^{2}$ $(7.8 \mathrm{~cm})$ to less than $45 \mathrm{~cm}^{2}(6.7 \mathrm{~cm})$.

Spatial DFEs were obtained by averaging SSH innovations within $2^{\circ} \times 2^{\circ}$ grid boxes. According to Fig. 3a, it appears that the maximum improvement by adding altimeters is achieved in areas with high variability. The addition of altimeters leads to significant improvements in the western boundary currents (WBC) and the Antarctic Circumpolar Current (ACC). In these regions, going from one to four assimilated altimeters reduces forecast errors by more than $200 \mathrm{~cm}^{2}$. On the other hand, centers of gyres and intertropical areas do not seem to be affected by a change in the number of assimilated altimeters. In highly dynamic areas, the impacts of adding a second and a third altimeter are clearly positive (Figs. 4a,c) for the system. Adding a fourth altimeter has fewer impacts (Figs. 4e,f). There is a positive improvement but the system can be locally deteriorated, as, for example, in the Agulhas Current or Kuroshio.

The assessment of forecast errors highlights the spatial heterogeneity of ocean variability, with an emphasis on highly dynamic areas (such as the WBC). To compare impacts spatially, it is preferable to use a normalized parameter such as NDFE [Eq. (2)]. This provides a very different perspective on the impacts of adding altimeters 


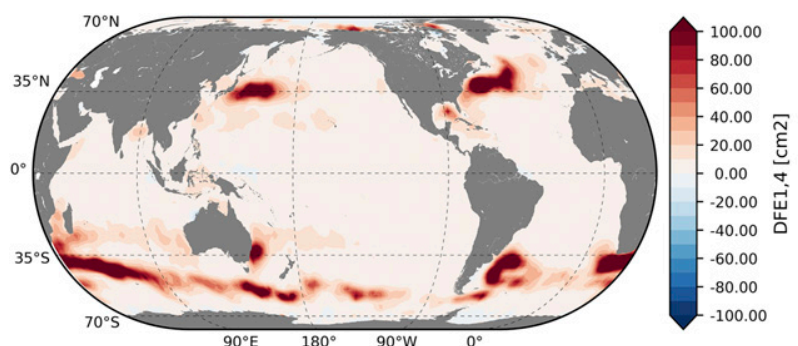

(a)

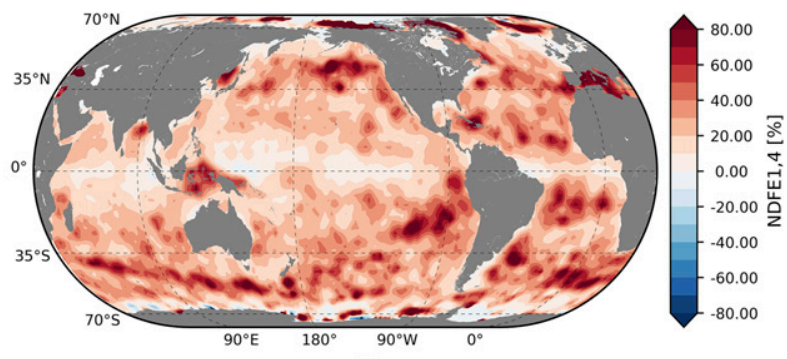

(b)

FIG. 3. (a) Differences of forecast errors between OSE1v4 and OSE4v4 (DFE 1,4 ) and (b) normalized differences of forecast errors between OSE1v4 and OSE4v4 (NDFE 1,4$)$.

in the system. Indeed, the benefits are not limited to regional areas but observed over almost the entire ocean. Comparing OSE1 and OSE4, it is calculated that the assimilation of four altimeters reduces forecast errors by about $30 \%$ regarding the local weekly variability (Fig. 3b). However, in the equatorial ocean, where the variability is mainly driven by atmospheric forcing and

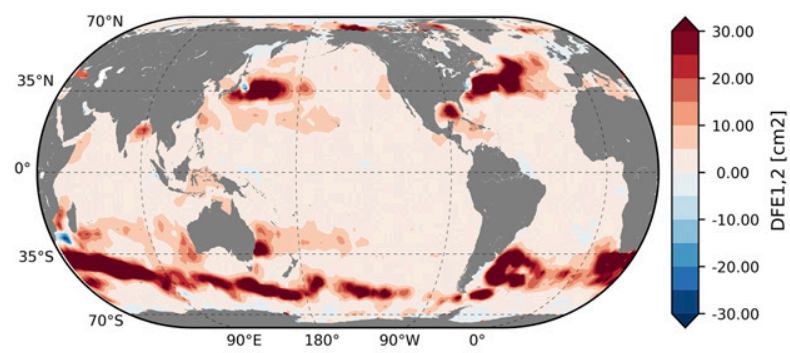

(a)

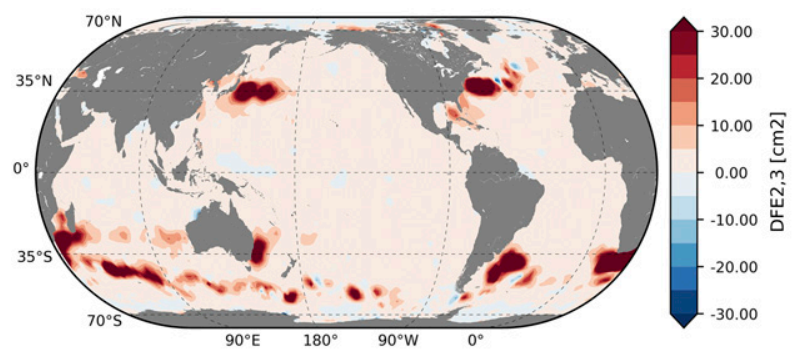

(c)

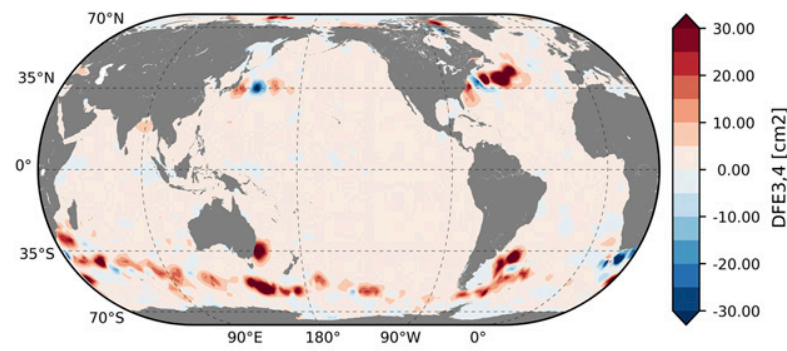

(e) dominated by tropical waves, the reduction in normalized errors is less. Conversely, in some regions such as the ACC front or the Mediterranean basin, the multiple altimeter data assimilation shows a very strong impact with a NDFE close to $80 \%$. If we look again at the impact of the fourth altimeter, the benefit is clearly positive. In the South Pacific, it can reach 15\%.

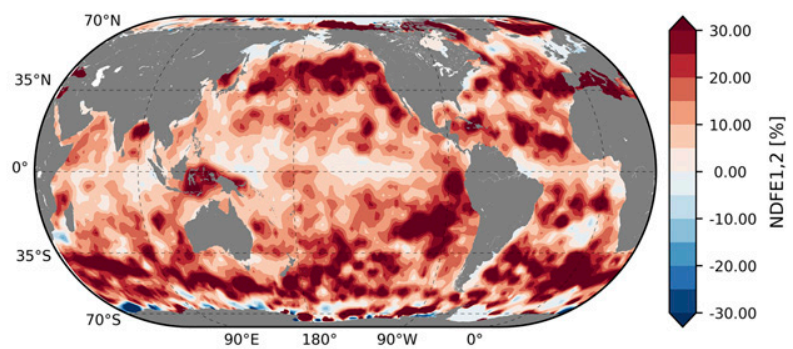

(b)

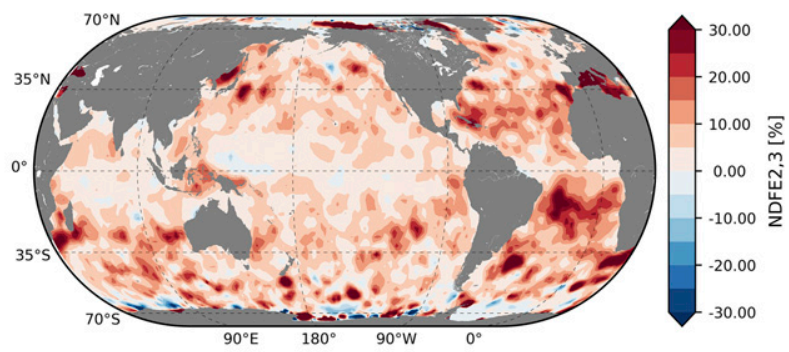

(d)

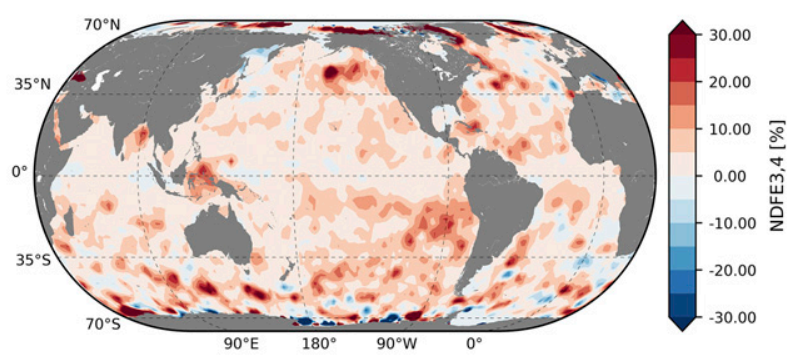

(f)

FIG. 4. Differences of (left) forecast errors (a) DFE ${ }_{1,2}\left(\right.$ OSE1v4 - OSE2v4), (c) DFE 2,3 (OSE2v4 - OSE3v4), and (e) DFE ${ }_{3,4}$ (OSE3v4 - OSE4v4) and (right) normalized forecast errors (b) $\mathrm{NDFE}_{1,2}$, (d) $\mathrm{NDFE}_{2,3}$, and (f) $\mathrm{NDFE}_{3,4}$. 


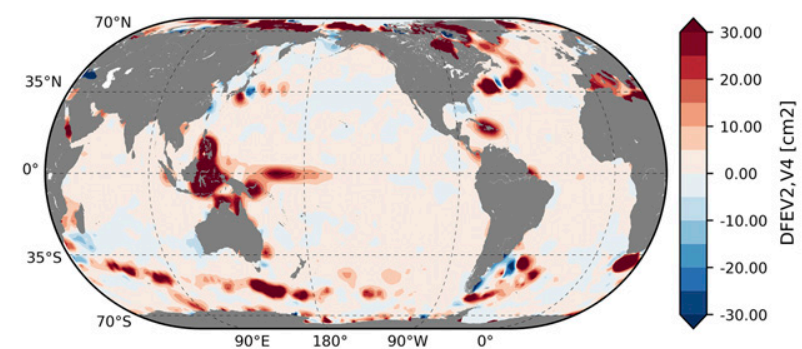

(a)

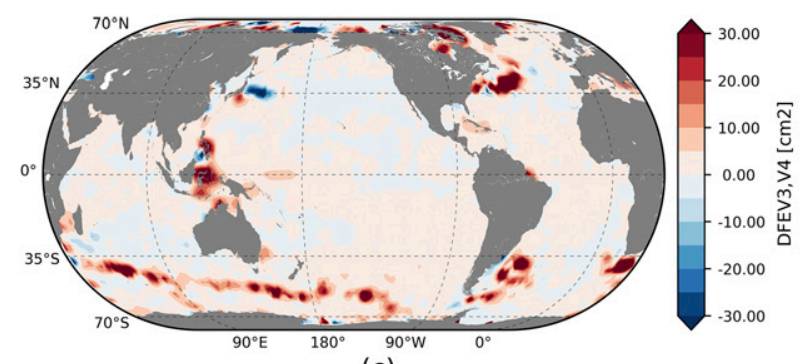

(c)

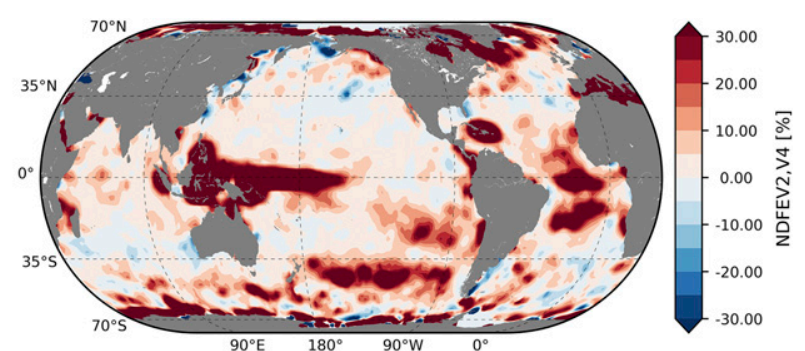

(b)

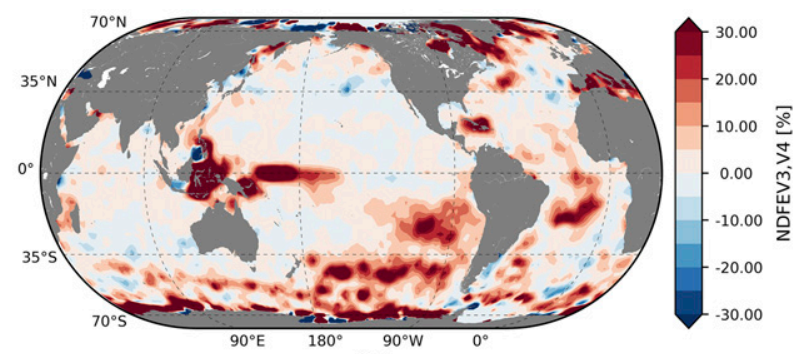

(d)

FIG. 5. Differences of (left) forecast errors (a) DFE $\mathrm{V}_{\mathrm{V}, \mathrm{V} 4}(\mathrm{OSE} 4 \mathrm{v} 2-\mathrm{OSE} 4 \mathrm{v} 4)$ and (c) $\mathrm{DFE}_{\mathrm{V} 3, \mathrm{~V} 4}(\mathrm{OSE} 4 \mathrm{v} 3-\mathrm{OSE} 4 \mathrm{v} 4)$ and (right) normalized forecast errors (b) $\mathrm{NDFE}_{\mathrm{V} 2, \mathrm{~V} 3}$ and (d) $\mathrm{NDFE}_{\mathrm{V} 3, \mathrm{~V} 4}$.

By now considering OSE4v2-OSE4v4, we compare the impacts of the MDT with the same methodology. According to Fig. 2, going from MDTv3 to MDTv4 has similar consequences on the overall forecast error as the addition of a fourth altimeter in the constellation. Error reduction by upgrading the MDT, replacing MDTv2 with MDTv4, is even greater. For example, in September 2014, the one-time impact of the MDT can reach the same level as the addition of two altimeters in the assimilation system. Spatial DFEs, presented in Fig. 5, show that changes in the MDT solution lead to a reduction in forecast error at the same locations. It is particularly evident where MDT improvements are strong, such as in seas around the Caribbean islands, the Gulf Stream, the Malvinas Current, or the ACC. However, it appears that the change from MDTv3 to MDTv4 in the Kuroshio induces a noticeable increase in the error.

Finally, we show that changes in MDT in Indonesian seas have a strong local impact, leading to a reduction in forecast errors in the area but also in the western Pacific equatorial basin (Fig. 5). In terms of NDFE, the system is improved by more than $30 \%$ in the region by going from MDTv2 to MDTv4. As discussed in Lellouche et al. (2013, 2018a), uncertainties on MDT in the Indonesian seas lead to major changes in our assessment of the ocean equatorial dynamic in the western Pacific. In addition, the comparison between modeled velocities and those derived from the position of drifting buoys (not shown here) reveals that the assimilation of the updated MDTv4 reduces velocity biases in the region, restoring the dynamics of the north equatorial current/countercurrent in the western Pacific.

\section{b. Forecast skill}

The ability of a system to forecast can also be assessed by comparing forecast skills that are often used in meteorology. This parameter evaluates the ability of a dynamic model to forecast the ocean state after $N$ days by comparing it with the persistence (the extension of the ocean's state at the beginning of the forecast window in our case). As the starting point of the forecast is determined by the analysis of previous assimilation cycles, forecast skill is thus a good indicator for the assessment of OSEs. While NDFE takes into account the local average variance, forecast skill uses the quadratic difference between two different times to normalize a forecast error [Eq. (3)].

Figure 6 shows the overall averaged forecast skills for the six OSEs as a function of the forecast day. All OSEs show a skill centered on 0.88 and decreasing over time. The general magnitude of the forecast skill means that, on average, the model is about 10 times better than persistence. The decreasing behavior is expected and illustrates that, given the uncertainties on the initial state of the ocean at the beginning of the cycle, in the dynamic model itself, the system slowly drifts away from reality (estimated from observations). Rather than directly comparing OSEs in terms of skill, it is even more relevant to assess the impacts in terms of forecast days. Thus, from Fig. 6, we estimate that for a given skill, going from one to two assimilated altimeters allows the system to save about 3 forecast days. In the same way, we estimate that the assimilation of a third altimeter 


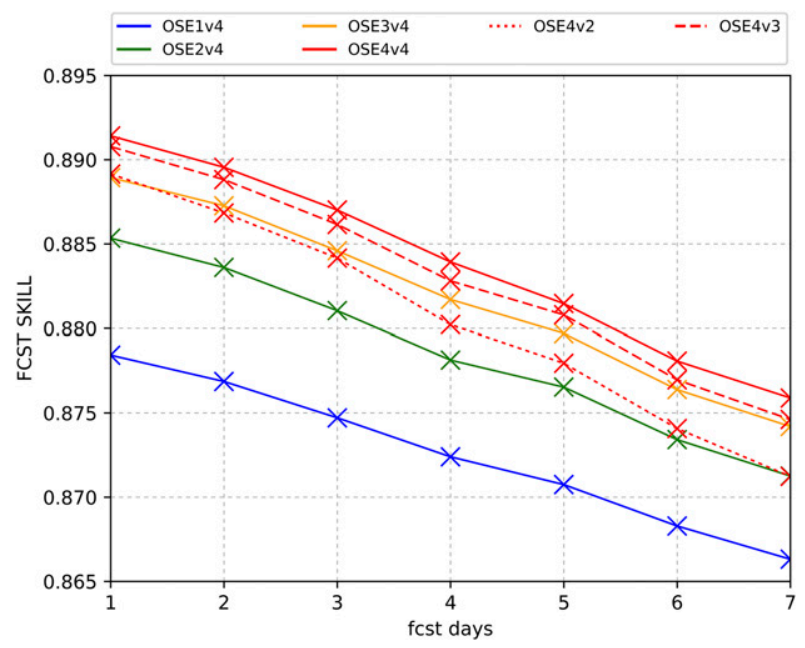

FIG. 6. Globally averaged forecast skill as a function of the forecast day for the OSE1v4 (blue full line), OSE2v4 (green full line), OSE3v4 (orange full line), OSE4v4 (red full line), OSE4v2 (red dotted line), and OSE4v3 (red dashed line).

allows the system to save about 1.5 days, then 1 additional day with a fourth. In terms of skills, the system thus shows comparable statistics at the first forecast day if it assimilates one altimeter and at the sixth day if it assimilates four altimeters.

Finally, we assess the impact of the assimilated MDT. According to Fig. 6, it seems that the changes in the MDT modify the magnitude of the decreasing behavior of the forecast skills. The use of the previous versions of the MDT tends to accelerate the drift of the system. The most relevant example is the decreasing behavior of the skill of OSE4v2. Indeed, around the first days of the forecast, OSE4v2 is close to OSE3v4 (three altimeters and MDTv4) and at the end of the assimilation window, the OSE is closer to OSE2v4 (two altimeters and MDTv4). In addition, going from MDTv2 to MDTv4 benefits the system to save about 1.5 days on average on the assimilation window.

\section{c. Spectral analysis}

In this section, we assess the impact of the number of altimeters and the change in MDT at different spatial scales of variability using spectral decomposition. We focus particularly on the impacts in the $75-250-\mathrm{km}$ range, the typical length scales of the mesoscale activity in the ocean. Considering the spatial resolution of the ocean model, the 75-km lower limit used to compute this diagnosis corresponds to the first resolved scales of the system. Following Dufau et al. (2016) and Xu and Fu (2012), spectra are computed along the tracks. Every $200 \mathrm{~km}$ along the track, a spectrum analysis is made using sections of $1000-\mathrm{km}$ continuous tracks.
Figure 7 shows the percentage of error in the mesoscale range compared to the observed mesoscale energy. Unlike previously in section 5a, we do not show here the difference in errors between two OSEs (such as DFEs). Each panel represents the error/observed signal ratio in the mesoscale range for a given OSE. Results clearly show that the error decreases with the assimilation of additional altimeters in the mesoscale range. In fact, with the assimilation of a single altimeter, the system is close to $100 \%$ error in the mesoscale, in most areas of the ocean. The best results are obtained with the assimilation of four altimeters, while changes in MDT do not have a significant impact. For example, in the Kuroshio Extension, going from one to four assimilated altimeters allows the system to reduce the forecast error from $85 \%$ to $45 \%$ in the mesoscale range. In general, the assimilation of each additional altimeter gradually reduces the error, except in the intertropical area where there is almost no improvement.

\section{d. Impacts of the MDT changes on ocean interior}

Differences between MDT OSEs in the 0-2000-m layer are analyzed in this section. The differences between OSEs were obtained by averaging, in grid boxes of $2^{\circ} \times 4^{\circ}$, all the statistics at the locations of in situ observations between the surface and 2000-m depth.

The Mercator Ocean assimilation scheme uses a multivariate approach to compute the incremental correction. Because of steric compensation effects, a change in the reference surface may affect the water column through the other variables. Figures 8 and 9 show the impacts on temperature and salinity, respectively, on the 0-2000-m layer between OSE4v2, OSE4v3, and the reference (best) experiment OSE4v4. While Figs. 8a, 8c, 9a, and 9c show the difference of salinity/temperature biases between OSEs and the reference, Figs. $8 \mathrm{~b}, 8 \mathrm{~d}, 9 \mathrm{~b}$, and $9 \mathrm{~d}$ show the difference of the biases magnitudes. These make it possible to show which OSE is closer to the observations.

Between the surface and 2000-m depth, OSE4v2 is fresher and warmer than OSE4v4 in most parts of the ocean, except in the Indonesian and Caribbean regions, where OSE4v2 is saltier and colder. For instance, south of $40^{\circ} \mathrm{S}$, the salinity of OSE $4 \mathrm{v} 2$ is reduced by about $8 \times 10^{-3} \mathrm{~g} \mathrm{~kg}^{-1}$ while the temperature is increased by $0.02^{\circ} \mathrm{C}$. OSE $4 \mathrm{v} 3$ shows less pronounced differences, particularly in terms of salinity. Nevertheless, OSE4v3 is slightly warmer than OSE4v4 in the South Pacific and South Atlantic $\left(+0.01^{\circ} \mathrm{C}\right)$. In fact, the differences in salinity and temperature between the OSEs show similar patterns to those presented in Fig. 1, which illustrates MDT differences. A positive (negative) difference of MDT tends to raise (lower) sea level values by adjusting temperature and salinity values in the deep layers. 


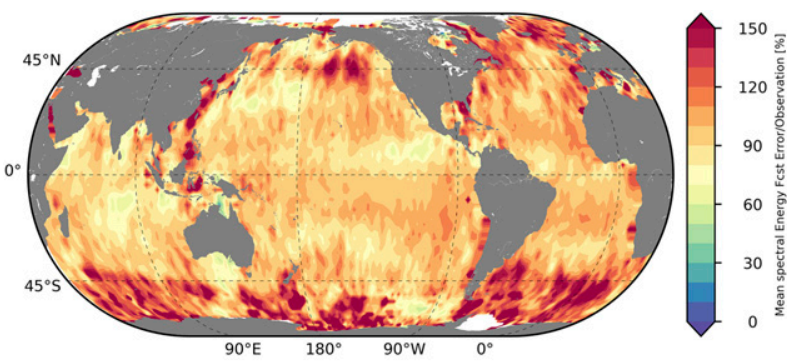

(a)

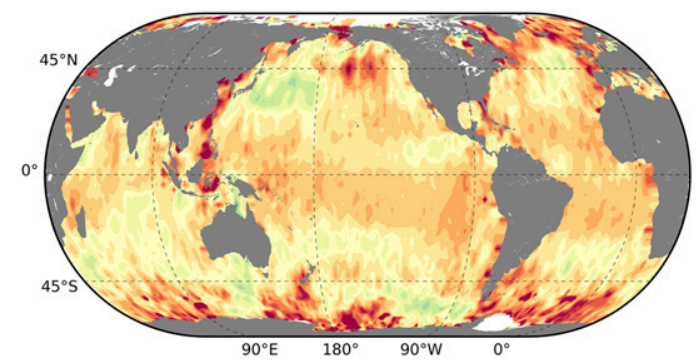

(c)

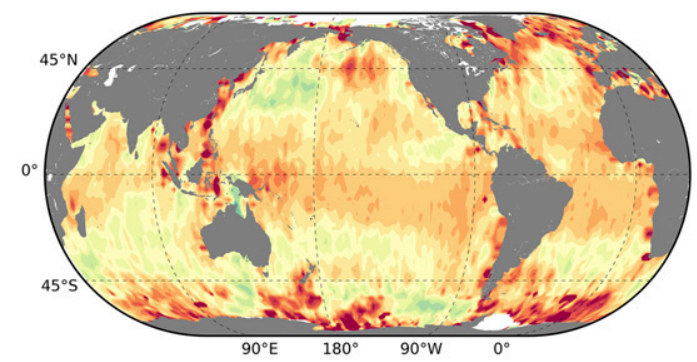

(e)

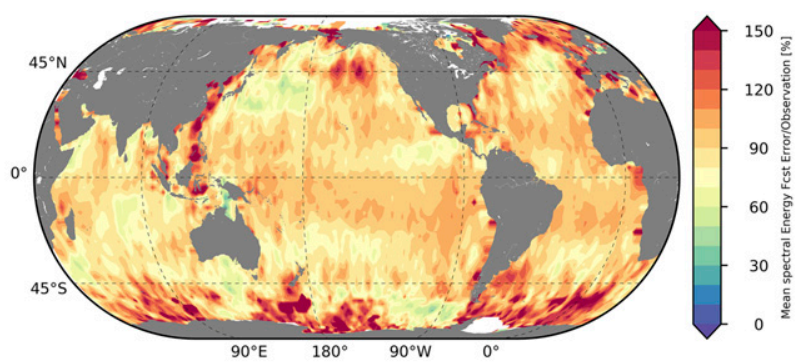

(b)

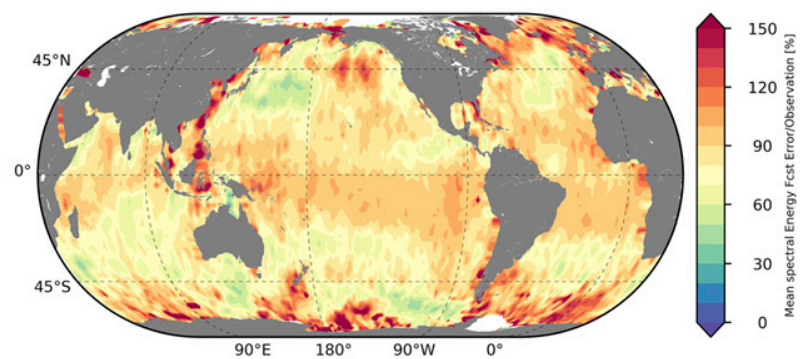

(d)

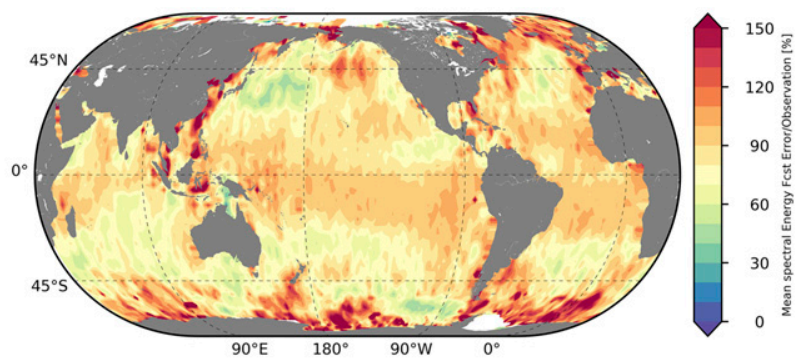

(f)

FIG. 7. Mean spectral energy of the forecast error in the 75-250-km-wavelength range with respect to the energy contained in assimilated SLA data in the same range for (a) OSE1v4, (b) OSE2v4, (c) OSE3v4, (d) OSE4v4, (e) OSE4v2, and (f) OSE4v3.

Above all, the assimilation of the up-to-date MDTv4 brings the system closer to the observations. According to Figs. $8 \mathrm{~b}$ and $8 \mathrm{~d}$, the difference of the temperature biases magnitudes between experiments assimilating the old MDTs and those assimilating MDTv4 is definitely positive. This shows that OSE4v4 is closer to in situ observations in almost every region of the global ocean. On average, it is also true for salinity (Fig. 9) but, in some areas, biases in OSE4v4 can be locally increased. Such local degradation may be due to a poor adjustment of the SSH error. As we have chosen to set it up from a four-altimeter experiment, it is possible that the $\mathrm{SSH}$ error is too low in some regions, compared to the other assimilated data.

\section{Summary and discussion}

Six 1-yr OSEs were designed to assess, on the one hand, the impacts of the number of altimeters, and on the other hand, the impact of the MDT in the global $1 / 4^{\circ}$
Mercator Ocean forecasting system. The first four experiments progressively assimilate one to four altimeters (Jason-2, CryoSat-2, Hayiang-2, and SARAL) with the new version of the MDT (MDTv4) in addition to SST maps and all available in situ data from CORA 4.1. Two additional OSEs were performed with 4 altimeters to assess the impact of the MDT. In these experiments, the MDTv4 were replaced by older versions, the MDTv3 (currently used in the operational system of Mercator Ocean) and MDTv2 (used in previous versions of the operational system).

Several studies have already highlighted the impacts of the numbers of altimeters on simpler mapping systems (with respect to the Mercator Ocean operational system), concluding that three (preferably four) altimeters were required for ocean monitoring. We here propose to deepen the analysis in a global forecast and analysis system, assessing the impacts at different spatial scales, at the surface and the interior ocean, and to 


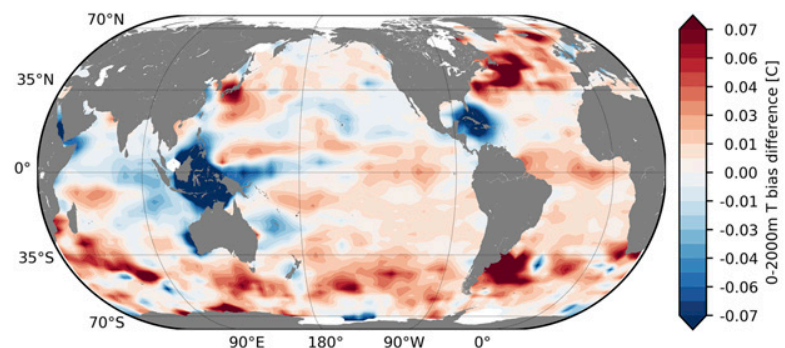

(a)

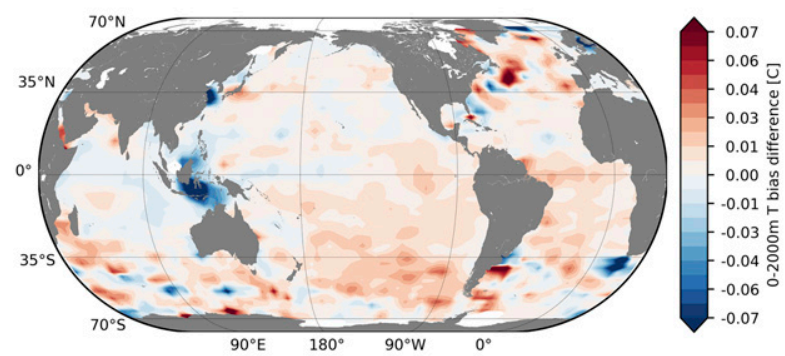

(c)

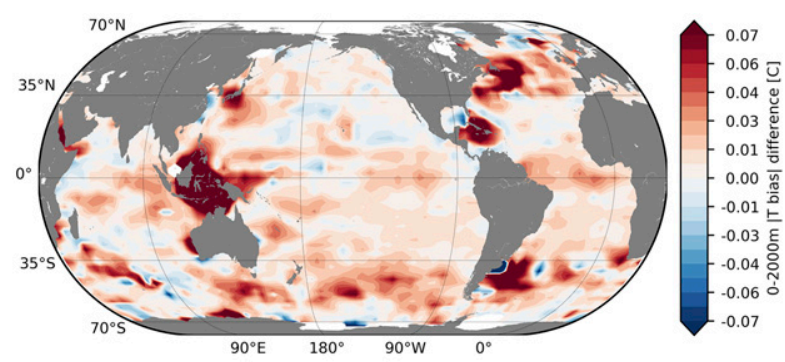

(b)

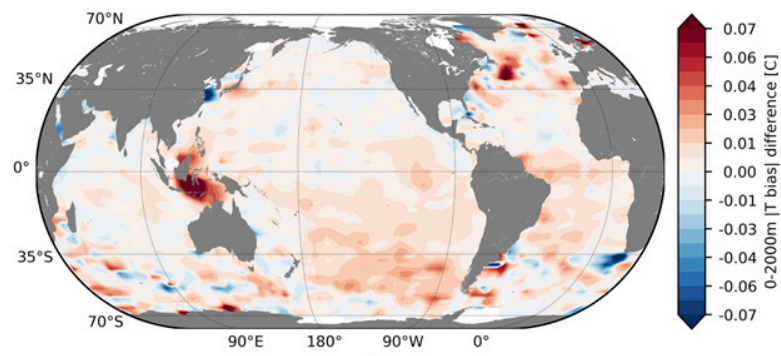

(d)

FIG. 8. Differences of (left) mean temperature biases in the 0-2000-m layer (a) between OSE4v2 and OSE4v4 and (c) between OSE4v3 and OSE4v4 and (right) magnitude of temperature biases (b) between OSE4v2 and OSE4v4 and (d) between OSE4v3 and OSE4v4.

compare it with the impact of the MDT, an essential component for assimilation of altimetry data.

The experimental setup of the OSE1v4-OSE4v4 does not strictly determine the impact of the number of assimilated altimeters, as an order of assimilation has been established for the altimeters $(J 2, J 2+C 2, J 2+C 2+$ $H Y 2$, and $J 2+C 2+H Y 2+A l)$. It strictly assesses the impact of a particular altimeter in the system. Ideally, multiple OSEs assimilating all altimeter combinations would have to be performed and the results averaged. Obviously, for cost reasons, it was not possible to carry out so many experiments. On the other hand, a degreeof-freedom signal analysis (DFS; not shown) showed that the amounts of information provided by the different

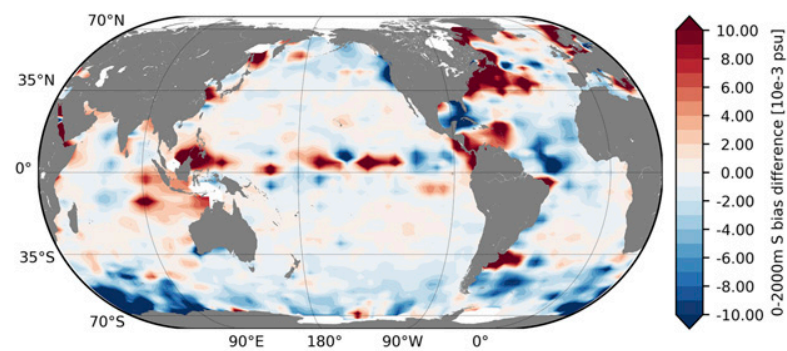

(a)

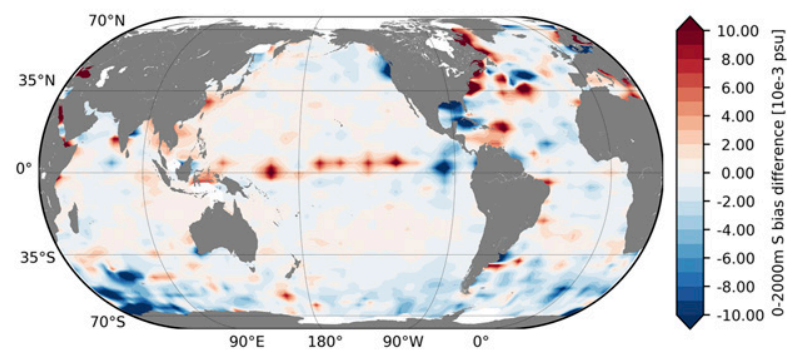

(c)

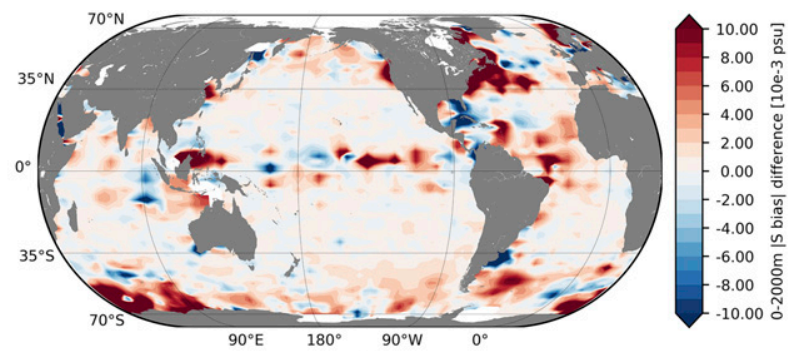

(b)

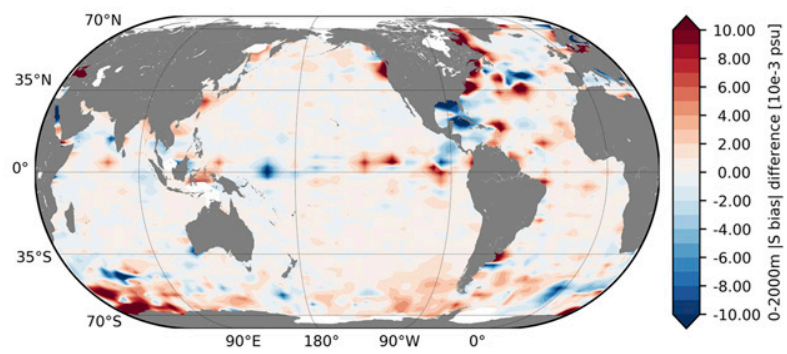

(d)

FIG. 9. Differences of (left) mean salinity biases in the 0-2000-m layer (a) between OSE4v2 and OSE4v4 and (c) between OSE4v3 and OSE4v4 and (right) magnitude of salinity biases (b) between OSE4v2 and OSE4v4 and (d) between OSE4v3 and OSE4v4. 
altimeters in the system were similar enough to make such a simplification.

The results regarding the number of assimilated altimeters are in agreement with those found in the literature, both in OSE and OSSE (Lea et al. 2014; Oke et al. 2015; Verrier et al. 2017). In the global $1 / 4^{\circ}$ Mercator Ocean forecasting system, compared to the one-altimeter configuration, the four-altimeter configuration reduces forecast error by about $30 \%$ on average, but it can reach more than $80 \%$ in WBC areas. The fourth altimeter has a significant impact because it reduces the error by $10 \%$ and saves one forecast day compared to the experiment assimilating three altimeters. In general, the most important improvements are made in highly dynamic areas such as the WBC or the ACC. The addition of altimeters has little impact in the equatorial ocean, however. In the mesoscale wavelength range, the spectral analysis shows that the system made an overall $100 \%$ error when assimilating a single altimeter. The best forecast is made by assimilating four altimeters. In the Kuroshio, for example, we show that it allows a gradual reduction in error from $85 \%$ to $45 \%$.

Nevertheless, this system seems to reach a plateau, with each additional altimeter having less impact. In the current $1 / 4^{\circ}$-resolution system of Mercator Ocean, a fifth or a sixth altimeter would probably not provide any useful information, even at smaller scales. One reason may be the resolution, which limits the model's ability to represent small ocean scales, but as we have shown in this study, uncertainties in MDT are also a limiting factor that are important to take into account. Overall, recent MDT updates allow the system to reduce the forecast error with a similar impact to that of adding a fourth altimeter in the constellation. The additional recent input of gravity data, altimetry and in situ measurements combined has improved the MDT, thus strongly reducing the $\mathrm{SSH}$ errors in both the WBC and the equatorial Pacific area. The ability to make longterm forecasts is also determined by the accuracy of the MDT. We have shown that, in addition to saving forecast days, the recent improvements of the MDT allow the system to improve the drift behavior of the model's forecast. Last, while altimetry data essentially drive the near-surface high-frequency variability, we have shown that MDT changes also have consequent slower effects concerning deeper 3D temperature and salinity fields through steric adjustments. In our opinion, this last point must be given the greatest consideration. This illustrates the difficulties of making the assimilation of different types of data coherent in a multivariate system. Moreover, ongoing works with biogeochemical configuration (forced by assimilated model) suggest that changes in the MDT solution could have very significant impacts on the biological production in the ocean. As interest in marine biogeochemical forecast is growing, it further strengthens our recommendations for improving our knowledge of the MDT. In conclusion, this study points out that a minimum of four altimeters is preferable to constrain the small-scale features in the ocean model but that an accurate MDT is also necessary to correctly use altimetry data in a multivariate assimilation system. Similar experiments are planned with the Mercator Ocean global highresolution system $\left(1 / 12^{\circ}\right)$. Given the effective resolution of the system, it is expected that the impact of multiple altimeters will be greater, especially in the mesoscale range.

Acknowledgments. This study was funded as part of a CNES-Mercator Ocean collaboration.

\section{REFERENCES}

Benkiran, M., and E. Greiner, 2008: Impact of the incremental analysis updates on a real-time system of the North Atlantic Ocean. J. Atmos. Oceanic Technol., 25, 2055-2073, https:// doi.org/10.1175/2008JTECHO537.1.

Bloom, S. C., L. L. Takas, A. M. Da Silva, and D. Ledvina, 1996: Data assimilation using incremental analysis updates. Mon. Wea. Rev., 124, 1256-1271, https://doi.org/10.1175/15200493(1996)124<1256:DAUIAU > 2.0.CO;2.

Cabanes, C., and Coauthors, 2013: The CORA dataset: Validation and diagnostics of in-situ ocean temperature and salinity measurements. Ocean Sci., 9, 1-18, https://doi.org/10.5194/ os-9-1-2013.

Carrère, L., and F. Lyard, 2003: Modelling the barotropic response of the global ocean to atmospheric wind and pressure forcing-Comparisons with observations. Geophys. Res. Lett., 30, 1275, https://doi.org/10.1029/2002GL016473.

Desroziers, G., L. Berre, B. Chapnik, and P. Polli, 2005: Diagnosis of observation, background and analysis-error statistics in observation space. Quart. J. Roy. Meteor. Soc., 131, 3385-3396, https://doi.org/10.1256/qj.05.108.

Dibarboure, G., M. I. Pujol, F. Briol, P. Y. Le Traon, G. Larnicol, N. Picot, F. Mertz, and M. Ablain, 2011: Jason-2 in DUACS: Updated system description, first tandem results and impact on processing and products. Mar. Geod., 34, 214-241, https:// doi.org/10.1080/01490419.2011.584826.

Ducet, N., and P.-Y. Le Traon, 2001: A comparison of surface eddy kinetic energy and Reynold stresses in the Gulf Stream and the Kuroshio Current systems from merged TOPEX/Poseidon and ERS-1/2 altimetric data. J. Geophys. Res., 106, $16603-$ 16 622, https://doi.org/10.1029/2000JC000205.

Dufau, C., M. Orsztynowicz, G. Dibarboure, R. Morrow, and P.-Y. Le Traon, 2016: Mesoscale resolution capability of altimetry: Present and future. J. Geophys. Res. Oceans, 121, 4910-4927, https://doi.org/10.1002/2015JC010904.

Greiner, E., and C. Périgaud, 1994: Assimilation of Geosat altimetric data in a nonlinear reduced-gravity model of the Indian Ocean. Part I: Adjoint approach and model-data consistency. J. Phys. Oceanogr., 24, 1783-1804, https://doi.org/10.1175/ 1520-0485(1994)024<1783:AOGADI>2.0.CO;2.

Large, W. G., and S. G. Yeager, 2009: The global climatology of an interannually varying air-sea flux data set. Climate Dyn., 33, 341-364, https://doi.org/10.1007/s00382-008-0441-3. 
Lea, D. J., P. Drecourt, A. K. Haines, and J. Martin, 2008: Ocean altimeter assimilation with observational and model-bias correction. Quart. J. Roy. Meteor. Soc., 134, 1761-1774, https:// doi.org/10.1002/qj.320.

—, M. J. Martin, and P. R. Oke, 2014: Demonstrating the complementarity of observations in an operational ocean forecasting system. Quart. J. Roy. Meteor. Soc., 140, 2037-2049, https://doi.org/10.1002/qj.2281.

Lellouche, J.-M., and Coauthors, 2013: Evaluation of global monitoring and forecasting systems at Mercator Océan. Ocean Sci., 9, 57-81, https://doi.org/10.5194/os-9-57-2013.

— Marine Service global ocean monitoring and forecasting realtime $1 / 12^{\circ}$ high-resolution system. Ocean Sci., 14, 1093-1126, https://doi.org/10.5194/os-14-1093-2018.

— resolution monitoring and forecasting system. New Frontiers in Operational Oceanography, E. Chassignet et al., Eds., GODAE OceanView, 563-592, https://doi.org/10.17125/gov2018.ch20.

Le Traon, P. Y., G. Dibarboure, G. Jacobs, M. Martin, E. Remy, and A. Schiller, 2017: Use of satellite altimetry for operational oceanography. Satellite Altimetry over Oceans and Land Surfaces, D. Stammer and A. Cazenave, Eds., CRC Press, 581-604.

Locarnini, R. A., and Coauthors, 2013: Temperature. Vol. 1, World Ocean Atlas 2013, NOAA Atlas NESDIS 73, 40 pp.

Madec, G., and Coauthors, 2008: NEMO. IPSL Tech. Rep.

Oddo, P., M. Adani, N. Pinardi, C. Fratianni, M. Tonani, and D. Pettenuzzo, 2009: A nested Atlantic-Mediterranean Sea general circulation model for operational forecasting. Ocean Sci., 5, 461-473, https://doi.org/10.5194/os-5-461-2009.

Oke, P. R., and Coauthors, 2013: Towards a dynamically balanced eddy-resolving ocean reanalysis: BRAN3. Ocean Model. 67, 52-70, https://doi.org/10.1016/j.ocemod.2013.03.008.

— , and Coauthors, 2015: Assessing the impact of observations on ocean forecasts and reanalyses: Part 2. Regional applications. J. Oper. Oceanogr., 8 (Suppl.), s63-s79, https://doi.org/ 10.1080/1755876X.2015.1022080.

Pascual, A., Y. Faugère, G. Larnicol, and P.-Y. Le Traon, 2006: Improved description of the ocean mesoscale variability by combining four satellite altimeters. Geophys. Res. Lett., 33, L02611, https://doi.org/10.1029/2005GL024633.
, M.-I. Pujol, G. Larnicol, P.-Y. Le Traon, and M.-H. Rio, 2007: Mesoscale mapping capabilities of multisatellite altimeter missions: First results with real data in the Mediterranean Sea. J. Mar. Syst., 65, 190-211, https://doi.org/10.1016/j.jmarsys.2004.12.004.

Reynolds, R. W., T. M. Smith, C. Liu, D. B. Chelton, K. S. Casey, and M. G. Schlax, 2007: Daily high-resolution blended analyses for sea surface temperature. J. Climate, 20, 5473-5496, https://doi.org/10.1175/2007JCLI1824.1.

Rio, M.-H., P. Schaeffer, F. Hernandez, and J.-M. Lemoine, 2005: The estimation of the ocean mean dynamic topography through the combination of altimetric data, in situ measurements and GRACE geoid: From global to regional studies. GOCINA Int. Workshop, Luxembourg City, Luxembourg, European Center for Geodynamics and Seismology.

_- S. Guinehut, and G. Larnicol, 2011: New CNES CLS09 global mean dynamic topography computed from the combination of GRACE data, altimetry, and in situ measurements. J. Geophys. Res., 116, C07018, https://doi.org/10.1029/2010JC006505.

_- A. Pascual, P.-M. Poulain, M. Menna, B. Barcelo, and J. Tintoré, 2014: Computation of a new mean dynamic topography for the Mediterranean Sea from model outputs, altimeter measurements and oceanographic in situ data. Ocean Sci., 10, 731-744, https://doi.org/10.5194/os-10-731-2014.

Storkey, D., and Coauthors, 2010: Forecasting the ocean state using NEMO: The new FOAM system. J. Oper. Oceanogr., 3, 3-15, https://doi.org/10.1080/1755876X.2010.11020109.

Tonani, M., N. Pinardi, C. Fratianni, J. Pistoia, S. Dobricic, S. Pensieri, M. de Alfonso, and K. Nittis, 2009: Mediterranean Forecasting System: Forecast and analysis assessment through skill scores. Ocean Sci., 5, 649-660, https://doi.org/10.5194/ os-5-649-2009.

Verrier, S., P.-Y. Le Traon, and E. Remy, 2017: Assessing the impact of multiple altimeter missions and Argo in a global eddy-permitting data assimilation system. Ocean Sci., 13, 1077-1092, https://doi.org/10.5194/os-13-1077-2017.

Xu, Y., and L.-L. Fu, 2012: The effects of altimeter instrument noise on the estimation of the wavenumber spectrum of sea surface height. J. Phys. Oceanogr., 42, 2229-2233, https:// doi.org/10.1175/JPO-D-12-0106.1.

Zweng, M. M., and Coauthors, 2013: Salinity. Vol. 2, World Ocean Atlas 2013, NOAA Atlas NESDIS 74, 40 pp. 